\title{
Understanding the spatial distribution of trichiasis and its association with trachomatous inflammation-follicular
}

\author{
Rebecca Mann Flueckiger ${ }^{1 *}$ (D), Emanuele Giorgi ${ }^{2}$, Jorge Cano ${ }^{1}$, Mariamo Abdala ${ }^{3}$, Olga Nelson Amiel ${ }^{3}$, \\ Gilbert Baayenda ${ }^{4}$, Ana Bakhtiari ${ }^{5}$, Wilfrid Batcho ${ }^{6}$, Kamal Hashim Bennawi ${ }^{7}$, Michael Dejene ${ }^{8}$, \\ Balgesa Elkheir Elshafie ${ }^{9}$, Aba Ange Elvis ${ }^{10}$, Missamou François ${ }^{11}$, André Goepogui ${ }^{12}$, Khumbo Kalua ${ }^{13}$, \\ Biruck Kebede ${ }^{14}$, Genet Kiflu' ${ }^{14}$, Michael P. Masika ${ }^{15}$, Marilia Massangaie ${ }^{3}$, Caleb Mpyet ${ }^{16,17}$, Jean Ndjemba ${ }^{11}$, \\ Jeremiah M. Ngondi ${ }^{18}$, Nicholas Olobio ${ }^{19}$, Patrick Turyaguma ${ }^{4}$, Rebecca Willis ${ }^{5}$, Souleymane Yeo ${ }^{10}$, \\ Anthony W. Solomon ${ }^{1}$ and Rachel L. Pullan ${ }^{1}$
}

\begin{abstract}
Background: Whilst previous work has identified clustering of the active trachoma sign "trachomatous inflammation-follicular" (TF), there is limited understanding of the spatial structure of trachomatous trichiasis (TT), the rarer, end-stage, blinding form of disease. Here we use community-level TF prevalence, information on access to water and sanitation, and large-scale environmental and socio-economic indicators to model the spatial variation in community-level TT prevalence in Benin, Cote d'Ivoire, DRC, Guinea, Ethiopia, Malawi, Mozambique, Nigeria, Sudan and Uganda.
\end{abstract}

Methods: We fit binomial mixed models, with community-level random effects, separately for each country. In countries where spatial correlation was detected through a semi-variogram diagnostic check we then fitted a geostatistical model to the $\Pi$ prevalence data including TF prevalence as an explanatory variable.

Results: The estimated regression relationship between community-level TF and TT was significant in eight countries. We estimate that a 10\% increase in community-level TF prevalence leads to an increase in the odds for $\pi$ ranging from 20 to $86 \%$ when accounting for additional covariates.

Conclusion: We find evidence of an association between TF and TT in some parts of Africa. However, our results also suggest the presence of additional, country-specific, spatial risk factors which modulate the variation in $\Pi$ risk.

Keywords: Trachoma, Trichiasis, Blindness, Visual impairment, Neglected tropical disease, Epidemiology, Global trachoma mapping project

\section{Background}

Trachoma is a blinding disease caused by recurrent ocular Chlamydia trachomatis infection, an organism that produces chronic inflammation of the tarsal conjunctiva. This is characterised by sub-epithelial follicles, which may meet the definition for the sign trachomatous inflammation-follicular (TF) [1]. TF is the sign whose prevalence in 1-9-year-olds is used to determine

\footnotetext{
* Correspondence: rebecca.flueckiger@lshtm.ac.uk

${ }^{1}$ London School of Hygiene and Tropical Medicine, London, UK

Full list of author information is available at the end of the article
}

whether public health-level interventions against active (inflammatory) trachoma are needed [2]. Through repeated reinfection [3, 4], conjunctival scarring may develop, eventually causing the eyelashes to turn inward and touch the globe, a state known as trachomatous trichiasis (TT). In-turned eyelashes that abrade the cornea can result in corneal opacity and blindness [1]. Corrective surgery $[5,6]$ or epilation [7] are used to manage TT.

Ocular chlamydial transmission is declining in many countries [8-11] suggesting exceptional progress in interrupting the transmission cycle. Until recently TT

(c) The Author(s). 2019 Open Access This article is distributed under the terms of the Creative Commons Attribution 4.0 International License (http://creativecommons.org/licenses/by/4.0/), which permits unrestricted use, distribution, and reproduction in any medium, provided you give appropriate credit to the original author(s) and the source, provide a link to the Creative Commons license, and indicate if changes were made. The Creative Commons Public Domain Dedication waiver (http://creativecommons.org/publicdomain/zero/1.0/) applies to the data made available in this article, unless otherwise stated. 
prevalence was only evaluated within the context of TF surveys [12]. As TT plays an essential role in trachoma elimination, it remains important to focus on areas where TT is still a public health problem, even in the absence of TF.

The pathogenesis of trachoma, implicitly conceptualized within WHO recommendations for district-level interventions, is of repeated episodes of active trachoma incrementally increasing the cumulative risk of TT. It should be noted that this may be a simplistic outlook on the complicated pathway to TT and additional elements may influence progression. However, active trachoma is a pre-requisite on TT's causal pathway, with moderate to high prevalences of TF being a proxy for current transmission of ocular C. trachomatis, and TT a proxy for historic transmission. The prevalence levels of these signs are therefore signals for $C$. trachomatis transmission intensity at different times (TF is current, and TT is historic and cumulative). Even though TF prevalence and TT prevalence are markers of transmission at different time points or over different time scales, in areas where antibiotic mass drug administration (MDA) for trachoma [13] has not yet occurred, it is often assumed that ocular $C$. trachomatis transmission intensity has remained more or less constant over decades, and that TF prevalence and TT prevalence will therefore closely correlate. This assumption is reasonable if access to water, sanitation, hygiene and anti-chlamydial antibiotics at community level have been constant or have changed only gradually. However, such an assumption is not always valid $[14,15]$.

Many national programmes [8] have successfully reduced TF prevalence in children aged 1-9 years below the elimination threshold of $5 \%$ [16] in some or many districts. To eliminate trachoma as a public health problem, district-level TT prevalence must also be reduced below $0.2 \%$ in adults aged $\geq 15$ years [16]. Whether or not active trachoma and TT are public health problems are two separate questions. In Nigeria, for example, 94 local government areas in six states mapped through the Global Trachoma Mapping Project (GTMP) yielded district-level TF prevalence estimates below the elimination threshold and district-level TT prevalence estimates above the threshold [17-23]. This is attributable to historic transmission intensity being considerably higher than the contemporary one. It is important to better understand the factors associated with high TT burden, so as to develop more targeted control interventions. Understanding where TT cases are likely to occur could help to guide strategic placement of TT intervention services.

Thanks to the GTMP, there has been an increasing availability of high quality geolocated trachoma and water, sanitation and hygiene (WASH) data. The GTMP was launched in December 2012 with the aim of mapping the global prevalence of trachoma in all suspected-endemic districts, through completion of population based prevalence surveys. It systematically collected trachoma and WASH data across 1546 districts in 29 countries, nearly exclusively in areas where control activities, including antibiotic MDA, had not yet occurred [24]. These data can be used to further our understanding of TT distribution.

In this study, we attempted to identify risk factors that, in addition to TF, might associate with variation in community-level TT prevalence. To this end we fit binomial mixed models, with random effects at community level, to GTMP baseline data from ten countries. We then test for residual spatial correlation and, in countries where this is detected, use geostatistical methods in order to model the variation in TT prevalence between countries.

\section{Methods \\ Data}

Ten GTMP collaborating countries provided data for this study: Benin, Cote d' Ivoire, Democratic Republic of the Congo (DRC), Ethiopia, Guinea, Malawi, Mozambique, Nigeria, Sudan and Uganda. Data provided were from 15,051 clusters (or communities) within 624 trachoma elimination intervention-naïve evaluation units (EUs) (Table 1). Individual-level information on the presence or absence of TF and TT, as well as water and sanitation access of geolocated households, were provided.

Community-level TT prevalence was calculated as the ratio between the number of adults aged $\geq 15$ years with trichiasis in at least one eye and the number of adults aged $\geq 15$ years examined. Community-level TF prevalence was calculated as the ratio between the number of children aged 1-9 years with TF in at least one eye and the number of children aged 1-9 years examined.

Physical and social environmental factors are hypothesized to play an important role in the natural history of trachoma. These factors could conceivably alter rate of progression to TT (Fig. 1).

Facial cleanliness is a well-established association of TF [25-30]. Access to water is necessary to facilitate personal hygiene practices. Previous studies have found an association between distance to water and risk of trachoma [25, 31-33]. There is mixed evidence on higher density populations of Musca sorbens, the fly vector for ocular C. trachomatis, being associated with a greater risk of trachoma [27, 34]. M. sorbens prefers to breed on human faeces left exposed on the soil $[35,36]$ and so it may be that latrine ownership has a protective association against active trachoma [37]. For this analysis, community-level WASH indicators were created 
Table 1 Summary of GTMP data included in the analysis

\begin{tabular}{|c|c|c|c|c|c|c|c|}
\hline \multirow[t]{2}{*}{ Country } & \multirow{2}{*}{$\begin{array}{l}\text { No. of } \\
\text { communities }\end{array}$} & \multicolumn{3}{|c|}{ TF in children aged 1-9years } & \multicolumn{3}{|c|}{$\Pi$ in adults aged $\geq 15$ years } \\
\hline & & No. examined & No. positive (\%) & $\begin{array}{l}\text { No. communities } \\
\text { prevalence } \geq 5 \%\end{array}$ & No. examined & No. positive (\%) & $\begin{array}{l}\text { No. communities with } \\
\text { prevalence } \geq 0.2 \%\end{array}$ \\
\hline Benin & 213 & 18,781 & $1594(8.5 \%)$ & $94(44.1 \%)$ & 16,170 & $254(1.6 \%)$ & $89(41.8 \%)$ \\
\hline Cote d'Ivoire & 256 & 17,658 & 1829 (10.4\%) & $174(68 \%)$ & 18,771 & $39(0.2 \%)$ & $26(10.2 \%)$ \\
\hline DRC & 1023 & 74,142 & $7022(9.5 \%)$ & $610(59.6 \%)$ & 52,200 & $1137(2.2 \%)$ & $511(50 \%)$ \\
\hline Ethiopia & 4480 & 186,308 & $40,131(21.5 \%)$ & 3119 (69.6\%) & 289,230 & $4711(1.6 \%)$ & $2154(48.1 \%)$ \\
\hline Guinea & 295 & 19,488 & $832(4.3 \%)$ & $98(33.2 \%)$ & 21,955 & $66(0.3 \%)$ & $53(18 \%)$ \\
\hline Malawi & 1948 & 82,185 & $3437(4.2 \%)$ & $561(28.8 \%)$ & 110,815 & $358(0.3 \%)$ & $259(13.3 \%)$ \\
\hline Mozambique & 696 & 34,602 & $2133(6.2 \%)$ & $297(42.7 \%)$ & 35,895 & $155(0.4 \%)$ & $117(16.8 \%)$ \\
\hline Nigeria & 5364 & 337,962 & $10,070(3 \%)$ & $1105(20.6 \%)$ & 371,928 & 4815 (1.3\%) & 2035 (37.9\%) \\
\hline Sudan & 667 & 33,830 & $1394(4.1 \%)$ & $172(25.8 \%)$ & 40,501 & $327(0.8 \%)$ & 197 (29.5\%) \\
\hline Uganda & 109 & 6019 & $183(3 \%)$ & 26 (23.9\%) & 7445 & $21(0.3 \%)$ & 20 (18.3\%) \\
\hline Total & 15,051 & 810,975 & $68,625(8.5 \%)$ & $6256(41.6 \%)$ & 964,910 & $11,883(1.2 \%)$ & $5461(36.3 \%)$ \\
\hline
\end{tabular}

from the GTMP household-level WASH dataset (Appendix 1). The categorization of these indicators was informed by the WHO/UNICEF Joint Monitoring Programme for Water Supply and Sanitation (JMP) [38]. We calculated the prevalence of access to each categorized WASH indicator.

Previous studies have shown that lower precipitation levels and higher temperatures can lead to an increase in the risk of TF [39]. Therefore, we selected climate-related factors, including annual total precipitation, mean temperature, aridity index and potential evapo-transpiration for this analysis. Gridded maps at $1 \mathrm{~km}^{2}$ resolution of annual total precipitation and mean temperature were extracted from the WorldClim database [40]. The aridity index and potential evapo-transpiration (PET) raster datasets of $1 \mathrm{~km}^{2}$ resolution, were obtained from the Consortium for Spatial Information (CGIAR-CSI) [41]. CGIAR-CSI modelled aridity index and PET using the data available from WorldClim as input parameters.

It has been suggested that frequent sandstorms that occur in some areas of Sudan cause eye trauma [42]. Irritation of the eyes leads to rubbing with fingers which could potentially accelerate the progression of TT. Hence, in our analysis we consider the proportion of sand in

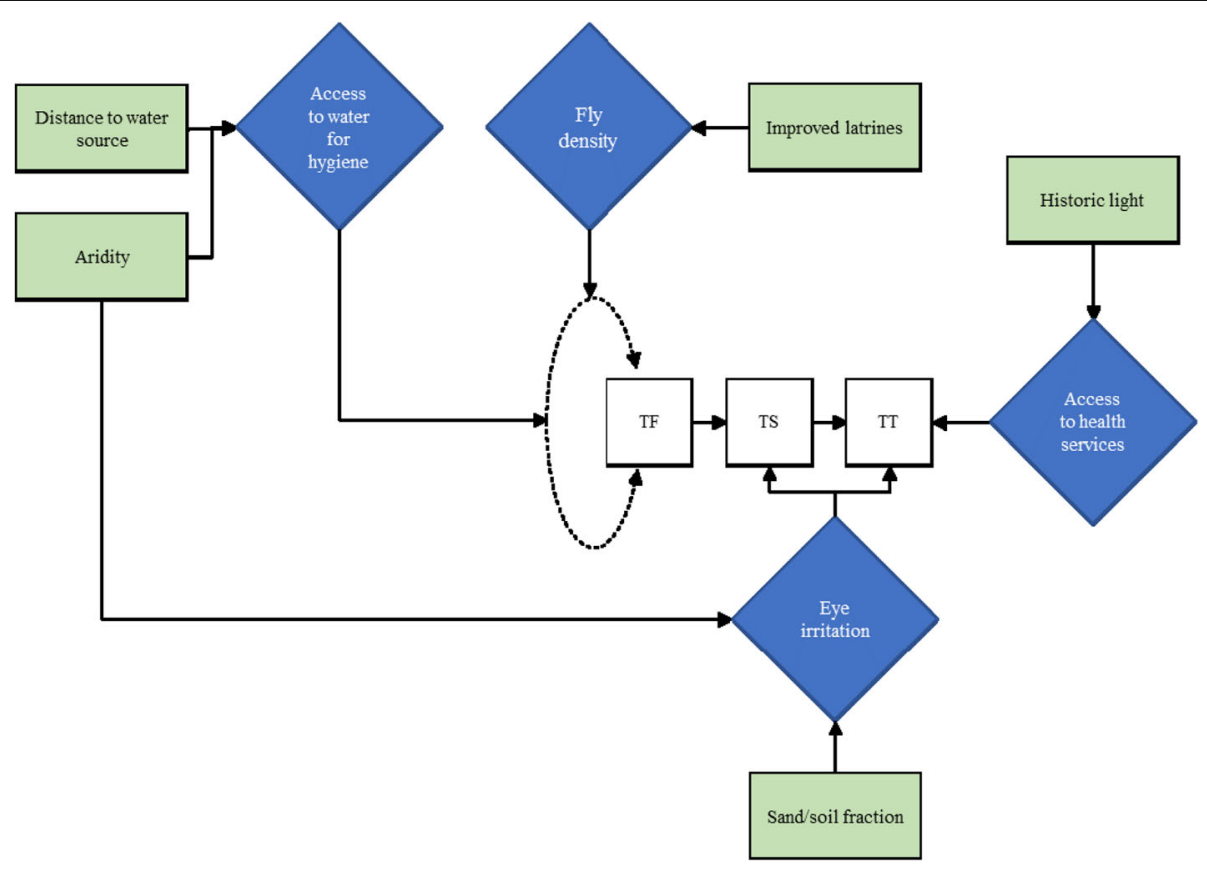

Fig. 1 Conceptual framework of environmental risk factors influencing progression to Tा 
topsoil as a potential risk factor for TT. These data were obtained from the ISRIC-World Soil Information project included in the Harmonized Soil Map of the World [43].

We speculate that access to healthcare and other services are associated with developed infrastructure, and therefore sought an infrastructure indicator. Light density at night has been shown to be correlated with local economic activity and gross production rate at different scales [44, 45]. Night light emission captured by the Operational Linescan System instrument on board a satellite of the Defence Meteorological Satellite Program was used as a proxy measure of poverty across Africa [46, 47]. A gridded map of straight line distances to stable lights, namely night light emissivity $>0$, was subsequently produced from the raw night light raster for 1997. This historic year was chosen because we were interested in a measure of infrastructure during the childhood of survey participants, rather than that at the time of the surveys themselves and the mean age of participants is 36 years.

All the aforementioned environmental datasets were derived from georeferenced raster files, and converted to a standardized resolution of $5 \mathrm{~km} \times 5 \mathrm{~km}$. The georeferenced data were linked in ArcGIS 10.1 (ESRI, Redlands, CA, USA). When shrinkage of spatial resolution was needed for the $1 \mathrm{~km}^{2}$ resolution covariates, we estimated the mean value in a $5 \mathrm{~km} \times 5 \mathrm{~km}$ window using the aggregate tool in the Spatial Analyst toolbox of ArcGIS 10.1 (Appendix 2).

To identify collinearity among the selected variables, we used the variance inflation factor (VIF) [48], defined as

$$
V I F_{j}=\frac{1}{1-R_{j}^{2}}
$$

where $R_{j}{ }^{2}$ is the fraction of explained variance in the $j$-th explanatory variables by the other explanatory variables.

\section{Model formulation}

Let $p_{i}$ denote the probability of having TT, $\beta_{0}$ is the intercept and $U_{i}$ is community-level unstructured random effects (let i denote the i-th community). We fit the following nested binomial mixed models, where $\gamma$ TFi is the regression coefficient for the effect of TF prevalence on the log-odds of TT:

$$
\begin{aligned}
& M 1: \log \left(\frac{p_{i}}{1-p_{i}}\right)=\beta_{0}+U_{i} ; \\
& M 2: \log \left(\frac{p_{i}}{1-p_{i}}\right)=\beta_{0}+\gamma T F_{i}+U_{i} ; \\
& M 3: \log \left(\frac{p_{i}}{1-p_{i}}\right)=\beta_{0}+\gamma T F_{i}+\sum_{j=1} \beta_{j} d_{i j}+U_{i},
\end{aligned}
$$

where $d_{i j}$ in $M 3$ are the explanatory variables described in the previous section. We use the log-likelihood ratio test to select among the three models defined above.

In fitting M3, we also carried out variable selection using a backward stepwise approach, starting from the mixed effects model with all the variables included. The likelihood-ratio test was used to test for the significance of each variable, with terms removed one by one until all those remaining were significant at $5 \%$ level.

To assess the presence of residual spatial correlation, we first obtained a point estimate of the community-level unstructured random effects $U_{i}$ from the best model identified in the previous step, and then computed the empirical semi-variogram. A semivariogram provides insights into the rate of decay of spatial autocorrelation in the data. It does this by computing the mean squared difference between pairs of residuals as a function of the distance between their associated geographical locations. A flat semi-variogram is interpreted as evidence against the presence of spatial correlation. To test for spatial correlation more formally, we also generated $95 \%$ confidence intervals under the assumption of spatial independence. These intervals were obtained by computing semi-variograms on 1000 randomly permuted point estimates of $U_{i}$, while holding the geographical locations fixed.

In cases where we found evidence of spatial correlation, we fitted geostatistical binomial logistic models, in which $U_{i}$ was modelled as a spatial Gaussian process with a stationary and isotropic correlation function. All the geostatistical models were fitted in the PrevMap [49] package.

\section{Results}

The output for the cluster-level tests suggested that temperature, precipitation, aridity index, and PET interact with one another (Table 2). Since aridity was highly correlated with each of these indicators, we retained this variable and excluded the remainder.

The strength of association for variables in the full mixed effects model varied between countries (Table 3).

Table 2 Multicollinearity test results for gridded covariates

\begin{tabular}{ll}
\hline Variable & VIF \\
\hline Annual mean temperature & 5.4 \\
Annual total precipitation & 47.6 \\
Aridity Index & 62.3 \\
Potential evapo-transpiration & 6.4 \\
Euclidean distance to ground water & 1.2 \\
Sand/soil fraction & 2.0 \\
Stable Night Light (1997) & 1.2 \\
Accessibility & 1.3 \\
\hline
\end{tabular}




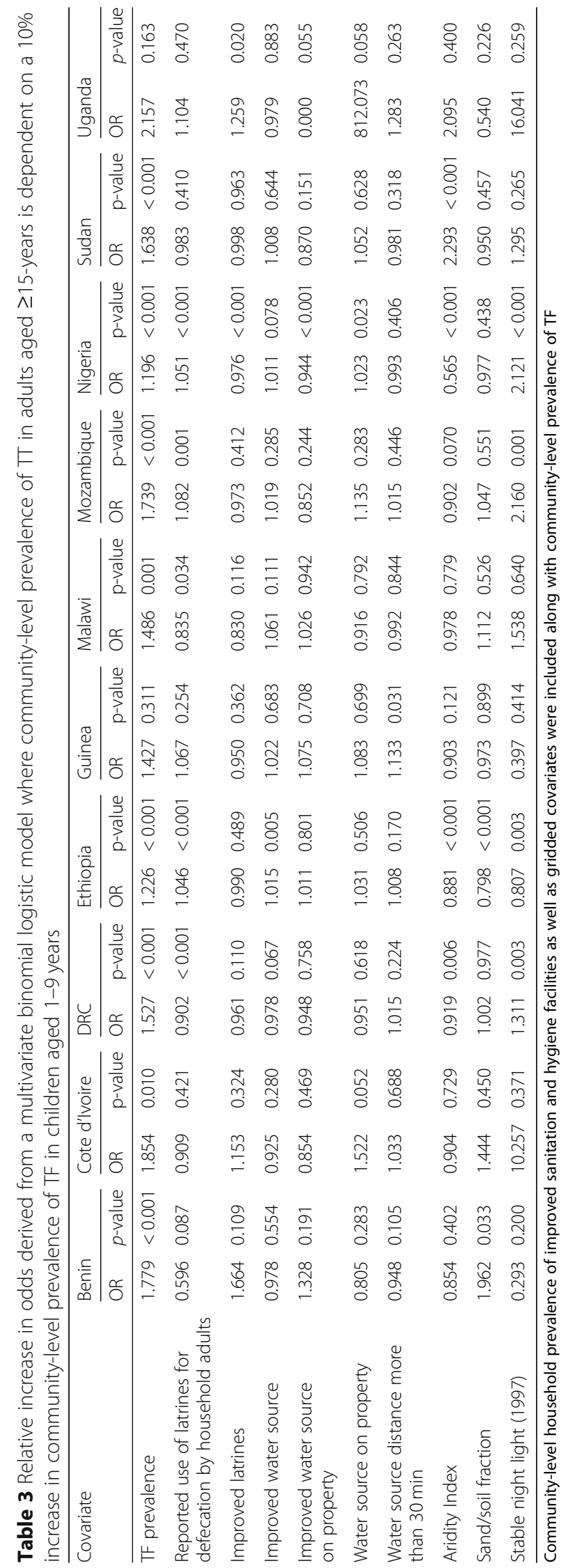


There was very strong evidence of association $(P<0.05)$ between community-level TF prevalence and TT prevalence in all countries except Guinea and Uganda. In contrast, there was evidence of association with access to latrines in 4 of 10 countries (DRC, Ethiopia, Mozambique and Nigeria $(p<0.01)$ ), with access to improved latrines in 2 countries (Nigeria and Uganda $(p<$ $0.05)$ ), and with water source variables in 3 countries (Ethiopia, Nigeria and Guinea $(\mathrm{p}<0.05))$. Observed relationships with environmental factors were equally heterogeneous, with associations observed with aridity index in DRC, Ethiopia, Nigeria and Sudan; and with sand/soil fraction only in Benin and Ethiopia. Night light was associated in DRC, Ethiopia, Mozambique and Nigeria.

The nested mixed effects models (Table 4) show that when TF was added as a fixed effect, the proportional reduction in variance ranged from 0.06 (Nigeria) to 0.42 (Benin). When environmental risk factors were added, the proportional change in variance ranged from 0.25 (Ethiopia) to 0.79 (Cote d'Ivoire). In all countries, variance continued to decrease as TF and then environmental risk factors were added to the model.

The best models, selected using the likelihood ratio test, are shown in Table 5. DRC, Ethiopia and Nigeria maintained the largest number of variables significant at the $5 \%$ level. These three countries also had the largest quantities of data available.

Semi-variograms generated with Pearson's residuals of the best fitting non-spatial binomial models suggest presence of residual spatial correlation in Benin, DRC, Ethiopia, Mozambique and Sudan. The 95\% confidence

Table 4 Comparison of variance explained by each mixed effects model

\begin{tabular}{|c|c|c|c|c|c|}
\hline & & & Null model & TF only model & $\begin{array}{l}\text { TF prevalence }+ \\
\text { risk factors model }\end{array}$ \\
\hline \multirow[t]{3}{*}{ Benin } & & Variance & 2.25 & 1.3 & 1.09 \\
\hline & Proportional reduction & Null model & & 0.42 & 0.52 \\
\hline & & TF only model & & & 0.16 \\
\hline \multirow[t]{3}{*}{ Cote d'Ivoire } & & Variance & 13.75 & 10.28 & 2.92 \\
\hline & Proportional reduction & Null model & & & 0.79 \\
\hline & & TF only model & & & \\
\hline \multirow[t]{3}{*}{ DRC } & & Variance & 1.52 & 1.23 & 1.05 \\
\hline & Proportional reduction & Null model & & 0.19 & 0.31 \\
\hline & & TF only model & & & 0.15 \\
\hline \multirow[t]{3}{*}{ Ethiopia } & & Variance & 1.22 & 1.01 & 0.92 \\
\hline & Proportional reduction & Null model & & 0.17 & 0.25 \\
\hline & & TF only model & & & 0.09 \\
\hline \multirow[t]{3}{*}{ Guinea } & & Variance & 1.88 & $1.87^{*}$ & 1.37 \\
\hline & Proportional reduction & Null model & & & 0.27 \\
\hline & & TF only model & & & \\
\hline \multirow[t]{3}{*}{ Malawi } & & Variance & 2.17 & 1.96 & 1.59 \\
\hline & Proportional reduction & Null model & & 0.1 & 0.27 \\
\hline & & TF only model & & & 0.19 \\
\hline \multirow[t]{3}{*}{ Mozambique } & & Variance & 4.45 & 3.52 & 3.06 \\
\hline & Proportional reduction & Null model & & 0.21 & 0.31 \\
\hline & & TF only model & & & 0.13 \\
\hline \multirow[t]{3}{*}{ Nigeria } & & Variance & 1.93 & 1.82 & 0.99 \\
\hline & Proportional reduction & Null model & & 0.06 & 0.49 \\
\hline & & TF only model & & & 0.46 \\
\hline \multirow[t]{3}{*}{ Sudan } & & Variance & 1.98 & 1.85 & 1.15 \\
\hline & Proportional reduction & Null model & & 0.07 & 0.42 \\
\hline & & TF only model & & & 0.38 \\
\hline
\end{tabular}




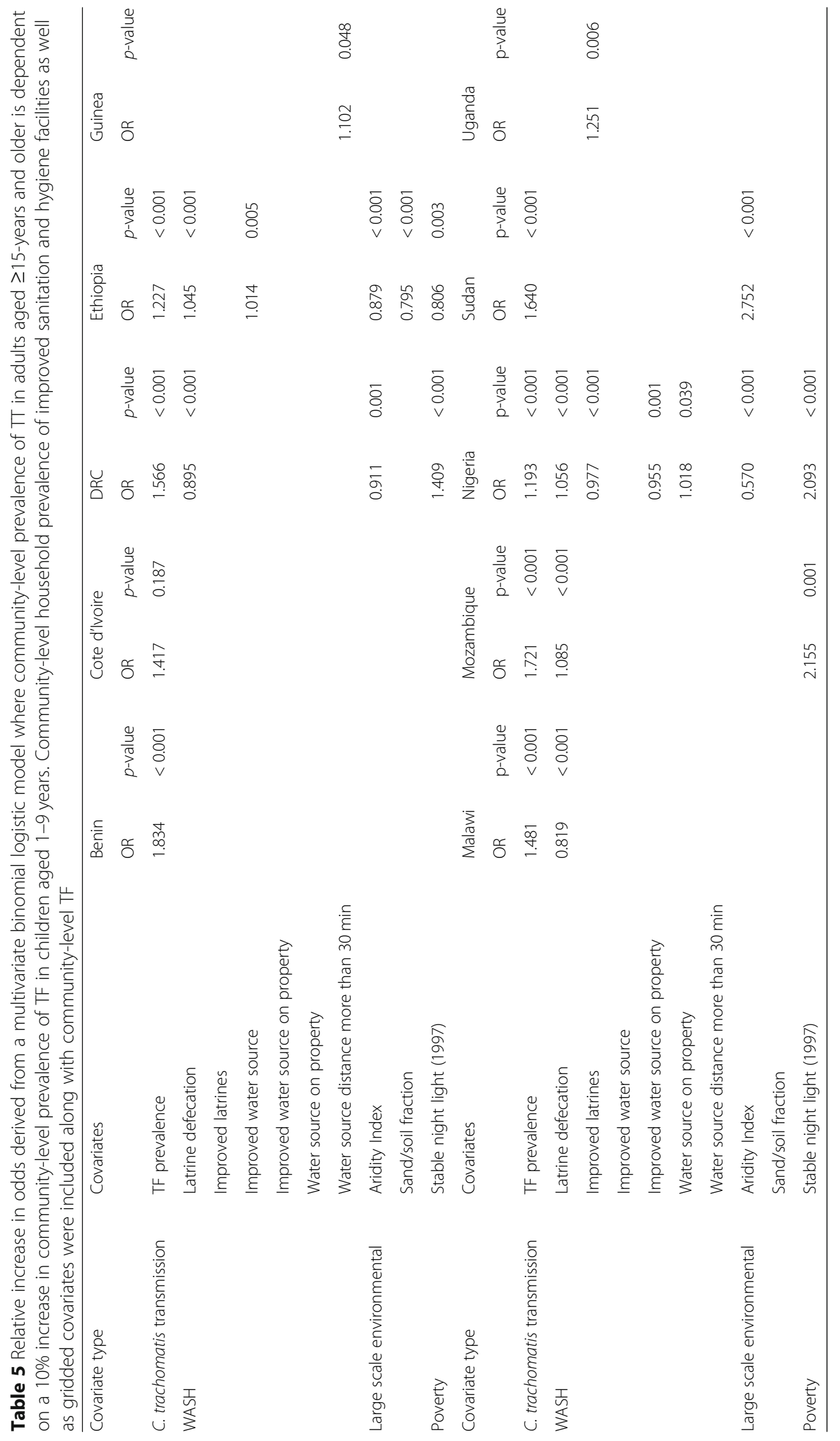




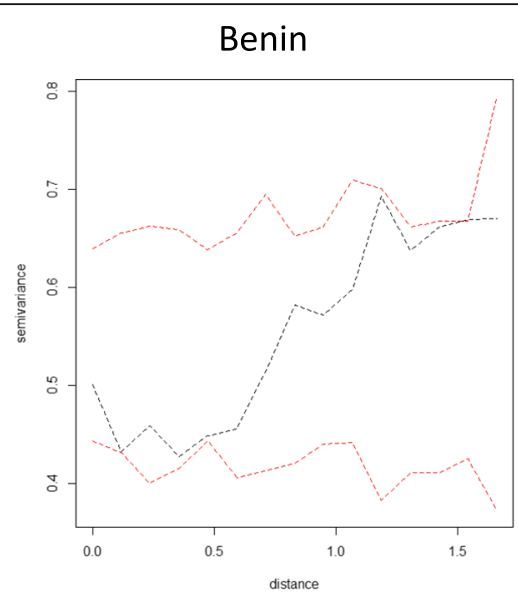

Ethiopia

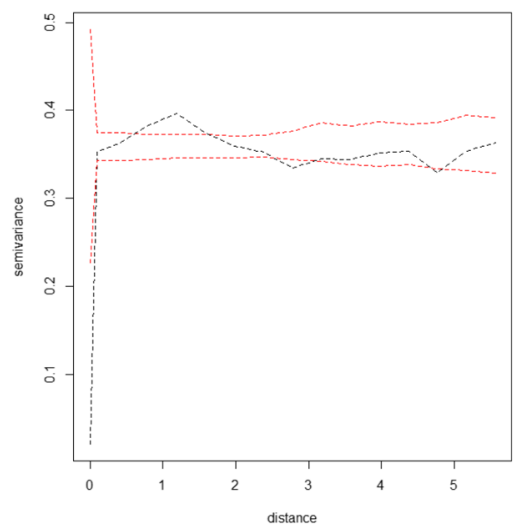

Sudan

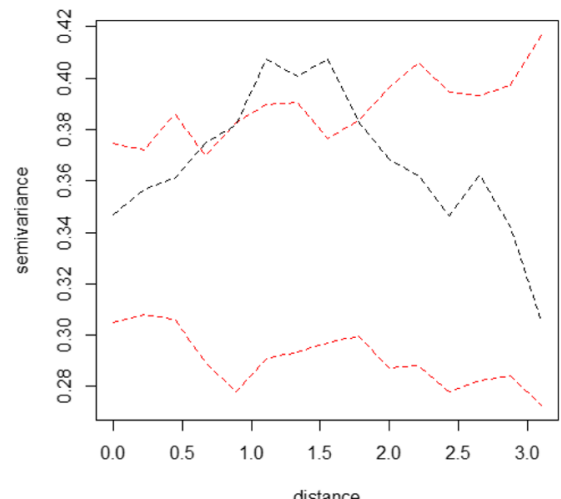

DRC

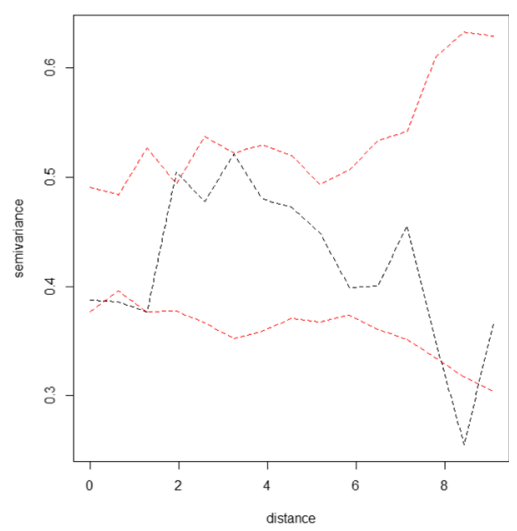

Mozambique

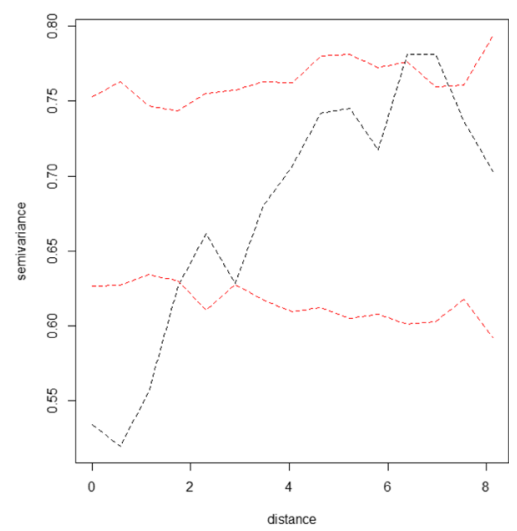

Fig. 2 Semi-variograms were generated with Pearson's residuals derived from the best fitting non-spatial mixed methods model. The 95\% confidence intervals (red dashed lines) and semi-variogram (black dashed line) created through generating 1000 simulations are displayed here. All distances are in kilometres

intervals generated under the assumption of spatial independence demonstrate spatial correlation in these countries (Fig. 2).

The distance at which spatial correlation fell below $5 \%$ ranged from $3.0 \mathrm{~km}$ (in Ethiopia) (95\% credible interval $1.6-6.0 \mathrm{~km}$ ) to $14.2 \mathrm{~km}$ (in Mozambique) (95\% credible interval $3.3-76.4 \mathrm{~km})$, corresponding with a very rapid decline in spatial correlation with distance at larger scales, after accounting for covariates (Table 6). 
Table 6 Scale of community-level $\pi$ prevalence spatial correlation in kilometres when accounting for covariates significant at the $5 \%$ level, by country with $95 \%$ confidence intervals

\begin{tabular}{lll}
\hline Country & scale of spatial correlation & $95 \%$ confidence intervals \\
\hline Benin & $3.2 \mathrm{~km}$ & $0.8-12.8 \mathrm{~km}$ \\
DRC & $7.7 \mathrm{~km}$ & $3.0-20.1 \mathrm{~km}$ \\
Ethiopia & $3.0 \mathrm{~km}$ & $1.6-6.0 \mathrm{~km}$ \\
Mozambique & $14.2 \mathrm{~km}$ & $3.4-48.9 \mathrm{~km}$ \\
Sudan & $2.8 \mathrm{~km}$ & $0.9-10.8 \mathrm{~km}$ \\
\hline
\end{tabular}

\section{Discussion}

We investigated factors associated with community-level TT prevalence after considering the community-level TF prevalence and spatial dependency, to try and understand what causes this variation. We demonstrated considerable variation in the relationship between community-level TF and TT. When accounting for other covariates, the mixed effects models demonstrated a strong association between community-level TF and TT in eight of ten countries. These models estimate that a $10 \%$ increase in community-level TF prevalence is associated with an increase in the odds for TT of 20 to $86 \%$, varying with setting. Benin, Cote d'Ivoire and Mozambique had exceptionally high increments in odds ratios with increasing TF, whereby a $10 \%$ increase in community-level TF prevalence was associated with an increase in TT odds of 78, 86 and $74 \%$ respectively. These high increments in odds ratios for TT lead us to speculate that reductions in TF prevalence in these environments will be quickly followed by a reduction in the incidence of TT. The relatively low increments in odds ratios in Ethiopia and Nigeria, where a 10\% increase in community-level TF prevalence associated with an increase in TT odds of only 23 and 20\% respectively, suggest a slight disconnect between historic and current transmission. This could be a signal of (1) a change in transmission dynamics over time, (2) population movement, (3) a pointer to the fact that we are using all-trichiasis as the dependent variable, rather than only trichiasis due to trachoma or (4) other factors are influencing TT aside from $C$. trachomatis. Further analysis is needed to explore the influence on the relationships that we observed here of including data on the presence or absence of trachomatous conjunctival scarring in eyes with trichiasis.

Importantly, in these models, the proportion of variance explained by TF ranges from $6 \%$ (in Nigeria) to $42 \%$ (in Benin). This range highlights the complex relationship of the distribution of TT and the distribution of TF. Environmental covariates, on average, explain an additional 9\% (in Ethiopia) to $46 \%$ (in Nigeria) of variance. Our models suggest that while community-level TF prevalence is generally the strongest single predictor of TT, it does not fully explain the variation in community-level TT prevalence, and implying that occasionally, high-TT-prevalence populations will be found where TF is rare. It has been widely observed that dry conditions (parameterized in our analysis as a low aridity index) is a risk factor for TF in children [31, 50-52]. We found an extension of this association in three of our countries, in the form of an association of low aridity index with increased TT prevalence. However, in Sudan we observed the phenomenon of an unexpectedly-positive association between community-level TT prevalence and aridity index. This counter-intuitive relationship may be attributed to coinfections facilitated in humid climates. It has been shown that coinfection with other bacteria [53], such as Streptococcus pneumoniae and Staphylococcus aureus [54], could influence progression of TT [55].

High levels of self-reported latrine use by adults, aridity index and 1997 night light had strongly significant associations with TT prevalence in only three of ten countries. This suggests that hygiene practices, dry climate and historic infrastructure may link to increased community-level TT prevalence in some settings, but generally they do not. Previous studies have clearly shown the association between access to WASH and risk of TF $[25,32,39,56]$ and so it is not surprising that our models, which account for TF prevalence, generally do not demonstrate significant residual associations between TT and WASH variables. The variation in direction of association may be an artefact of WASH improvements over time, or-hypothetically-existence of latrines themselves could contribute to facilitating M. sorbens breeding if the latrines are not appropriately maintained, thereby deterring some potential users whilst protecting householders from legal or peer pressure to build an adequate facility. The development of TT requires many previous C. trachomatis infections [4] and so populations that historically had poor WASH access may now have high TT burdens, even if the WASH situation has since improved.

Many other studies have identified correlates of high TF prevalence, including potential socio-economic, demographic and environmental risk factors [25, 32, 39, 56-58], and have explored TF's spatial distribution at different geographic scales [33, 52, 59-61]. However, few studies have specifically examined TT's environmental risk factors and spatial distribution $[42,62,63]$. These previous studies were limited by the amount of data they incorporated, and their conclusions therefore had constrained generalizability. Our models, developed using large datasets from ten countries with outcome data considered to be gold standard [64], reached similar conclusions and so provide additional validation to this previous work.

The variation between countries in directions of association of environment-related indicators and the variation in spatial structure indicate that fitting a single 
model to the whole set of data is inadvisable. These variations are presumably attributable to country context.

There may be several explanations for the inconsistency of associations between large-scale indicators and community-level TT seen between countries. Studies have shown that post-operative recurrence of TT $[55,65,66]$ and incidence of scaring $[67,68]$ may be important influencers of TT prevalence. It would be valuable for future models to further explore these elements. Our modelling approach did not capture recent or historical population movement. Migration could certainly play a role in the geographic distribution of TT. It is also important to note that different ethnic groups may have different progression rates to TT. For example, a study in the Gambia found a polymorphism in the TNF- $\alpha$ gene promoter was associated with scarring, and was found more frequently among Mandinkas than other ethnic groups [69].

We observed residual spatial correlation in only five countries (Benin, DRC, Ethiopia, Mozambique, and Sudan), suggesting that in the remaining countries there are no outstanding large-scale environmental factors influencing progression to TT.

In the geostatistical models, we identified a very rapid decline in spatial correlation with distance at larger scales, after accounting for covariates. This suggests that very closely adjacent communities have similar levels of TT.

\section{Conclusion}

The lack of consistent risk factors beyond communitylevel TF raises concerns that the models identified artefacts that are not generalizable, such as non-trachomatous trichiasis, or that the clinical history of trachoma varies substantially between settings. This underlines the importance of understanding local context when designing interventions for at-risk populations. Whilst our findings are not generalizable across countries, they can provide general direction for where to initiate case finding activities. As has been found in the Guinea Worm eradication program, active surveillance and case finding will be essential as trachoma elimination endpoints draw closer [70]; these activities become more expensive as prevalence drops [71]. This uniquely large and standardized analysis provides important insight into the variation in community-level TT distribution and identifies substantial variation in the relationship between community-level TF and TT prevalence. For some countries, important environmental risk factors were identified which can be used to inform case finding efforts, by providing insight into where TT cases are most likely to be found. Our findings suggest that in some countries it is possible to inform strategic location of TT management services, potentially improving efficiency of the end-game of trachoma elimination.

\section{Appendix 1}

Table 7 GTMP Water, Sanitation, and Hygiene indicators. Responses are classified as improved where marked with $X$

\begin{tabular}{ll}
\hline S1) Where do you and other adults in & 1) Shared or public latrine \\
the household usually defecate? & 2) Private latrine \\
number of households reporting & 3) No structure, outside \\
that adults living in the household & near the house \\
defecate in either a shared public & 4) No structure, in the \\
latrine or a private latrine / number & bush or field \\
of households enrolled in the survey & 9) Other
\end{tabular}

S2) Improved latrine: What kind of toilet facility do the adults in the household use? Observed.

number of households where an improved latrine is observed / number of households enrolled in the survey

H3) Improved Water source: In the dry season, what is the main source of water used by your household for washing faces?

number of households reporting to access improved water sources / number of households

enrolled in the survey

H4) Wash near: Washing water: If you collected water there to bring back to the house, how long does it take to go there, get water,

1) Flush/pour flush to piped sewer system

2) Flush/pour flush to $\quad X$ septic tank

3) Flush/pour flush to pit $\quad X$ latrine

4) Flush/pour flush to open drains

5) Flush/pour flush to $\quad X$ unknown place

6) Ventilated improved pit $\quad X$ latrine (VIP)

7) Pit latrine with slab $\quad X$

8) Pit latrine without slab/ open pit

9) Composting toilet

10) Bucket

11) Hanging toilet/hanging latrine

12) No facilities or bush or field

99) Other

1) Piped water into dwelling

2) Piped water into yard/pot

3) Public tap/standpipe $\quad X$

4) Tubewell/borehole $\quad X$

5) Protected dug well $\quad x$

6) Unprotected dug well

7) Protected spring

8) Unprotected spring

9) Rainwater collection

10) Water vendor

11) Surface water (e.g. river, dam, lake, canal)

99) Other

0) All face washing done at the water source

1) Water source in the yard $x$

2) Less than $30 \mathrm{~min}$

number of households reporting

access to improved water sources and those

water sources are on the premises /

number of households enrolled

3) Between $30 \mathrm{~min}$ and $1 \mathrm{~h}$

4) More than $1 \mathrm{~h}$

in the survey 


\section{Appendix 2}

\section{Climate:}

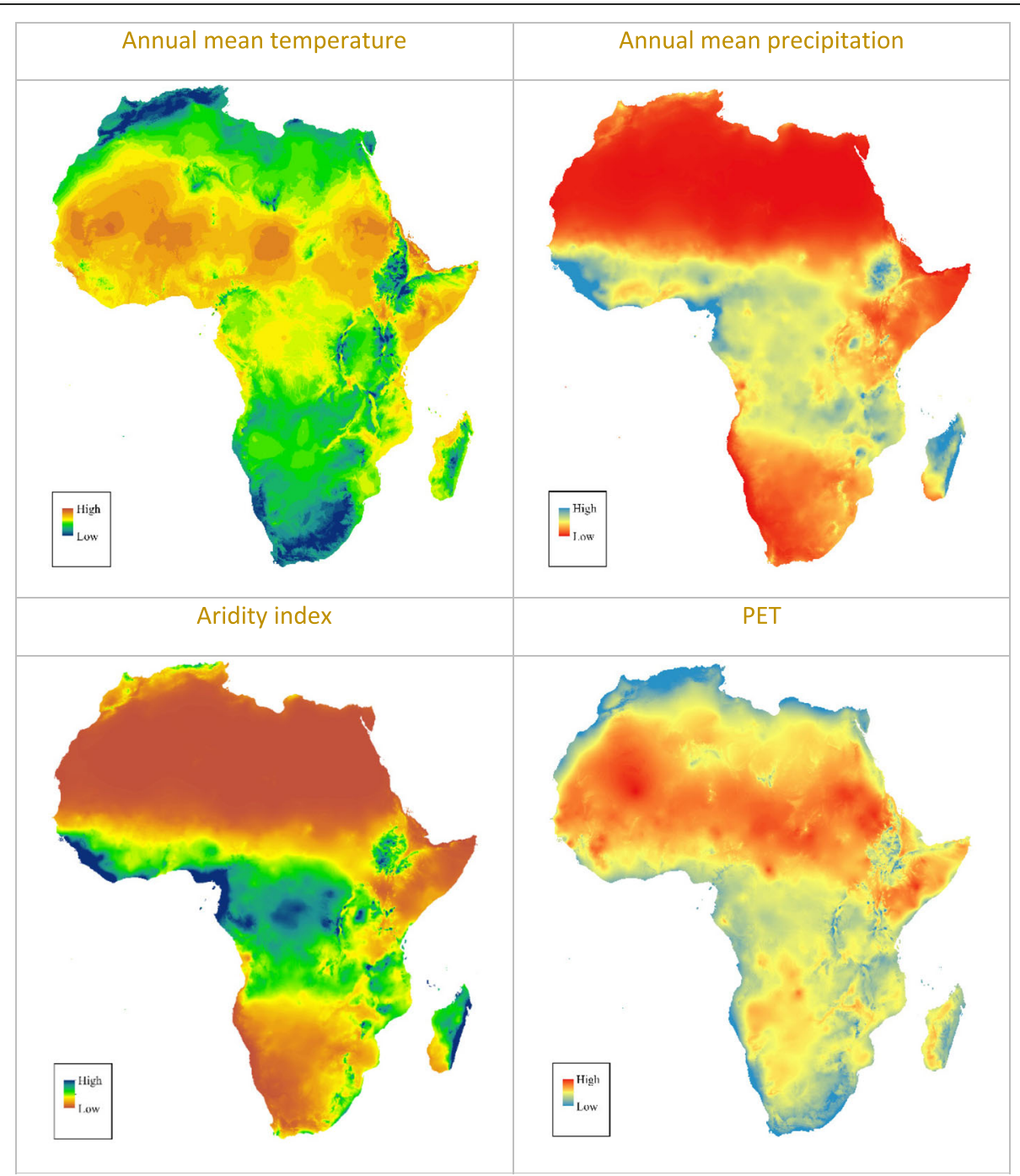

Fig. $35 \mathrm{~km}$ gridded climate raster maps. Data depicted in this map were obtained from the Consortium for Spatial Information (CGIAR-CSI) [41]. The georeferenced raster files were converted to a $5 \mathrm{~km} \times 5 \mathrm{~km}$ resolution and visualized by the manuscript authors using ArcGIS 10.1 (ESRI, Redlands, CA, USA) 
Water access:

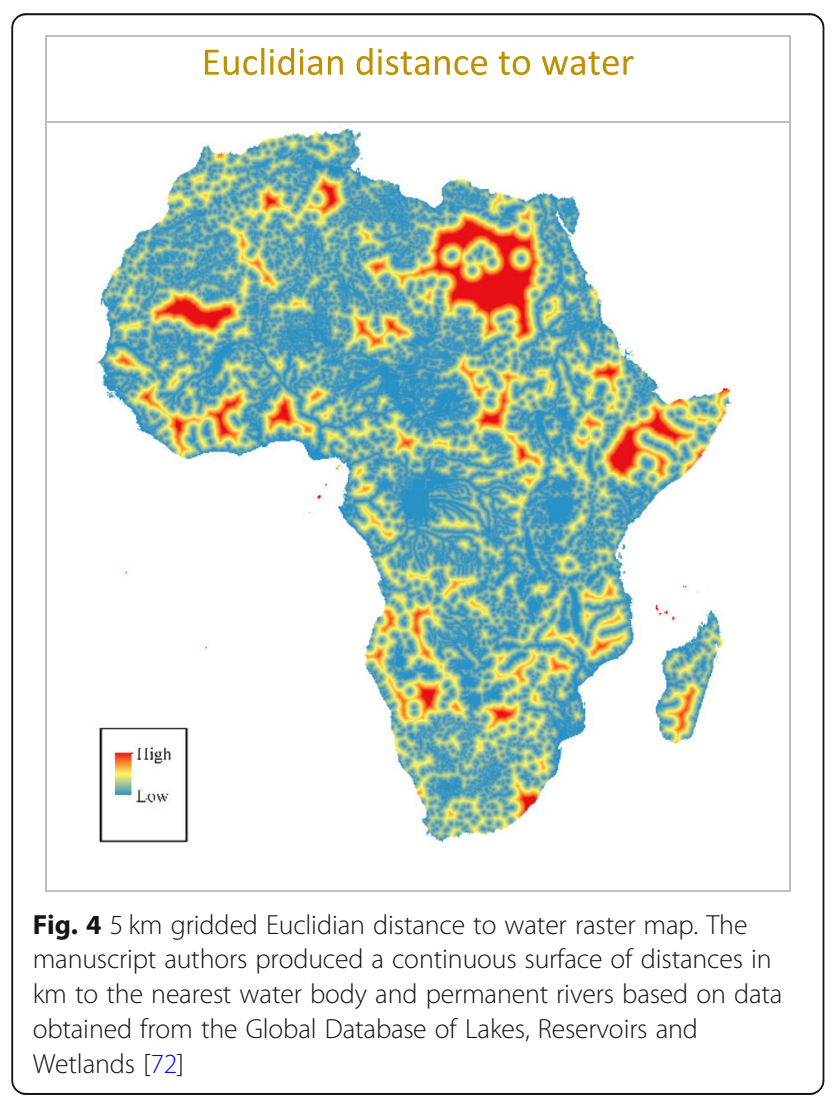

Soil composition (fraction and soil properties):

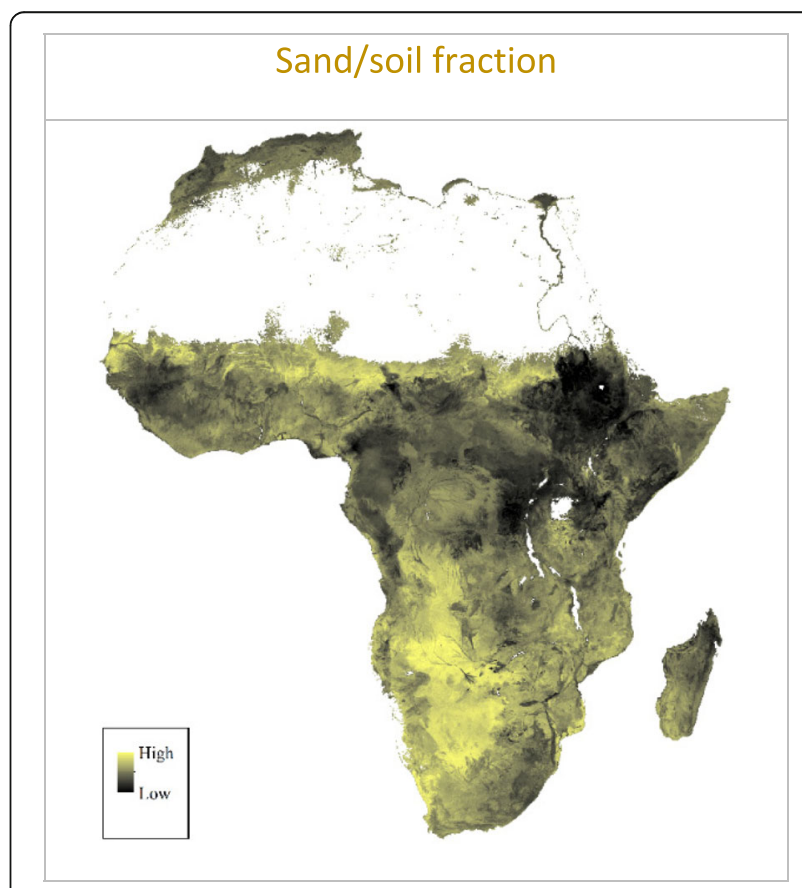

Fig. $55 \mathrm{~km}$ gridded soil composition sand fraction raster map. Data depicted in this map were obtained from the ISRIC-World Soil Information project included in the Harmonized Soil Map of the World [43]. The georeferenced raster files were converted to a $5 \mathrm{~km} \times 5 \mathrm{~km}$ resolution and visualized by the manuscript authors using ArcGIS 10.1 (ESRI, Redlands, CA, USA) 


\section{Remoteness:}

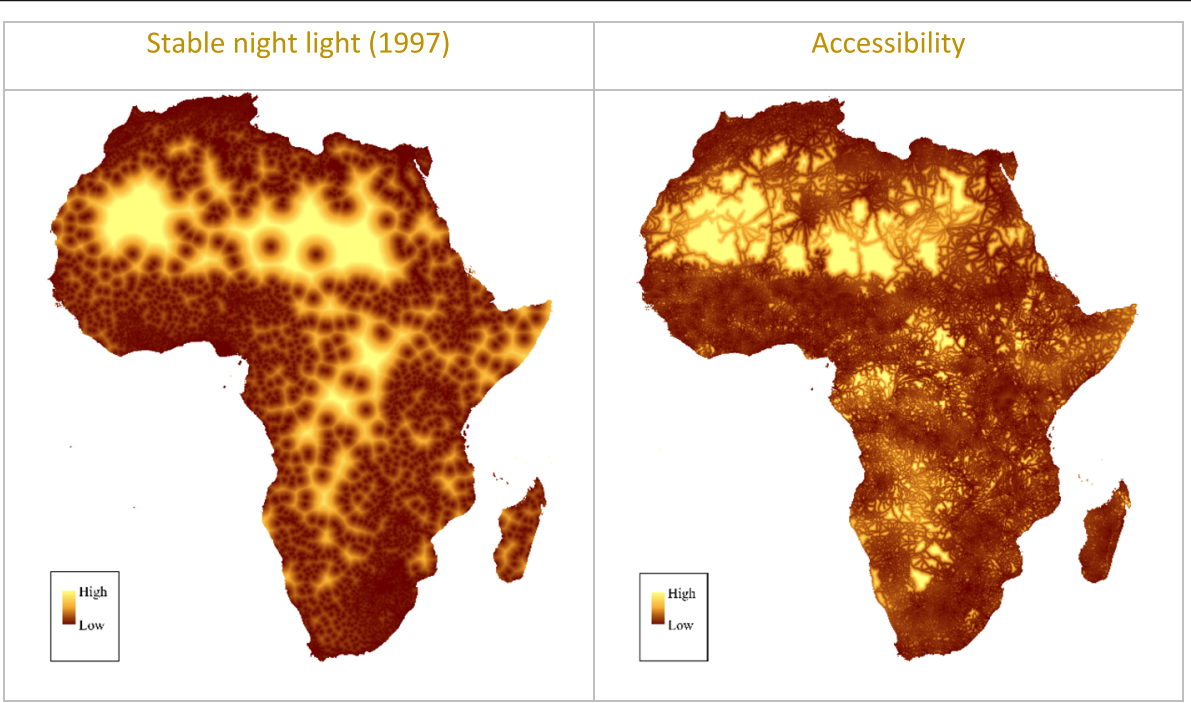

Fig. $65 \mathrm{~km}$ gridded remoteness raster maps. Data depicted in this map were obtained from the Operational Linescan System instrument on board a satellite of the Defence Meteorological Satellite Program [46, 47]. The georeferenced raster files were converted to a $5 \mathrm{~km} \times 5 \mathrm{~km}$ resolution and visualized by the manuscript authors using ArcGIS 10.1 (ESRI, Redlands, CA, USA)

\section{Abbreviations}

CGIAR-CSI: Consortium for spatial information; DRC: Democratic Republic of the Congo; EU: Evaluation unit; GTMP: Global trachoma mapping project; JMP: Joint monitoring programme for water supply and sanitation; MDA: Mass drug administration; PET: Potential evapo-transpiration; TF: Trachomatous inflammation-follicular; TT: Trachomatous trichiasis; VIF: Variance inflation factor; WASH: Water sanitation and hygiene

\section{Acknowledgements}

We thank the health ministries (or government-designated agencies) of Benin, Cote d'Ivoire, Democratic Republic of the Congo, Ethiopia, Guinea, Malawi, Mozambique, Nigeria, Sudan and Uganda for providing data used in this analysis.

We also thank Mathew Freeman and Josh Garn for their technical advice on questions relating to water, sanitation and hygiene.

\section{Funding}

The Global Trachoma Mapping Project (GTMP) supported collection of the data used in this study. The GTMP was funded by (1) a grant from the United Kingdom's Department for International Development (ARIES: 203145) to Sightsavers, and (2) the United States Agency for International Development (USAID), through the ENVISION project implemented by RTI International under cooperative agreement AID-OAA-A-11-00048, and the END in Asia project implemented by FHI360 under cooperative agreement number OAA-A-10-00051. AWS was a Wellcome Trust Intermediate Clinical Fellow (098521) at the London School of Hygiene \& Tropical Medicine. These funders had no role in the design, analysis and interpretation of the data presented here. The funders had no role in writing the manuscript. The authors alone are responsible for the views expressed in this article and they do not necessarily represent the views, decisions or policies of the institutions with which they are affiliated.

\section{Availability of data and materials}

The data that support the findings of this study are available from the corresponding Ministry of Health but restrictions apply to the availability of these data, which were used under license for the current study, and so are not publicly available. Data are however available from the authors upon reasonable request and with permission of corresponding Ministry of Health.

\section{Authors' contributions}

RMF, EG, JC and RLP made substantial contributions to the conception, design and analysis of the work. RMF drafted the work. AWS made substantial contributions to the conception of the work and interpretation of the data. MA, ONA, GB, AB, WB, KHB, MD, BEE, AAE, MF, AG, KK., B.K., G.K., M.P.M., M.M., C.M., J.N., J.M.N., N.O., P.T., R.W. and S.Y. made substantial contributions to the acquisition and interpretation of the data. All authors revising the draft critically for important intellectual content, had final approval of the version to be published, and agreed to be accountable for all aspects of the work in ensuring that questions related to the accuracy or integrity of any part of the work are appropriately investigated and resolved.

\section{Ethics approval and consent to participate}

Informed verbal consent was obtained from all participants. The fundamental purpose of the data collection was to guide the implementation of trachoma elimination programmes. Consent to participate allowed survey teams to examine both eyes of the consenting individual on one occasion only. For this reason, and because local partners with whom the fieldwork protocol was discussed believe that verbal consent is more acceptable than written consent in the largely illiterate rural populations amongst whom the surveys was conducted, we obtained informed verbal consent. All data collection was electronic, using an ODQbased Android phone application. Consent (or its refusal) was formally noted by a trained, registered data recorder, who has a unique identification number and a signature kept on file. At the conclusion of data collection for each evaluation unit, the recorder signed a statement affirming that informed verbal consent was appropriately obtained from each individual examined in the survey. The study and the verbal consent procedure was approved by the Research Ethics Committee of the London School of Hygiene \& Tropical Medicine (11909).

\section{Consent for publication}

Not applicable.

\section{Competing interests}

The authors have no proprietary or commercial interest in any materials discussed in this article. The authors alone are responsible for the views expressed in this article and they do not necessarily represent the views, decisions or policies of the institutions with which they are affiliated. 


\section{Publisher's Note}

Springer Nature remains neutral with regard to jurisdictional claims in published maps and institutional affiliations.

\begin{abstract}
Author details
${ }^{1}$ London School of Hygiene and Tropical Medicine, London, UK. ${ }^{2}$ Lancaster Medical School, Lancaster University, Lancaster, Lancashire, UK. ${ }^{3}$ Ophthalmology Department, Ministry of Health, Maputo, Mozambique . ${ }^{4}$ Trachoma Program, Ministry of Health, Kampala, Uganda. ${ }^{5}$ Task Force for Global Health, Decatur, GA, USA. ${ }^{6}$ Programme National de Lutte contre les Maladies Transmissibles, Ministère de la Santé, Cotonou, Benin. ${ }^{7}$ Prevention of Blindness Program, Federal Ministry of Health, Khartoum, Sudan. ${ }^{8}$ Michael Dejene Public Health Consultancy Services, Addis Ababa, Ethiopia. ${ }^{9}$ National Program for Prevention of Blindness, Federal Ministry of Health, Khartoum, Sudan. ${ }^{10}$ Programme National de la Santé Oculaire et de la lutte contre I'Onchocercose, Abidjan, Côte d'Ivoire. ${ }^{11}$ Direction de Lutte contre la Maladie, Kinshasa, Ministere de la Santé Publique, Kinshasa, Democratic Republic of Congo. ${ }^{12}$ Programmes National de Lutte contre l'Onchocercoses et les autres Maladies Tropicales Négligées, Ministère de la Sante, Conakry, Guinea . ${ }^{13}$ Blantyre Institute for Community Outreach, Blantyre, Malawi. ${ }^{14}$ Federal Ministry of Health, Addis Ababa, Ethiopia. ${ }^{15}$ Ministry of Health, Lilongwe, Malawi. ${ }^{16}$ Sightsavers Nigeria, Kaduna, Nigeria. ${ }^{17}$ Department of Ophthalmology, Jos University, Jos, Nigeria. ${ }^{18}$ RTI International, Dar es Salaam, United Republic of Tanzania. ${ }^{19}$ Nigeria Trachoma Elimination Program, Federal Ministry of Health, Abuja, Nigeria.
\end{abstract}

Received: 25 July 2018 Accepted: 24 March 2019

Published online: 30 April 2019

\section{References}

1. Mabey DC, Solomon AW, Foster A. Trachoma. Lancet. 2003;362(9379):223229. doi: https://doi.org/10.1016/S0140-6736(03)13914-1. PubMed PMID: 12885486.

2. Thylefors B, Dawson CR, Jones BR, West SK, Taylor HR. A simple system for the assessment of trachoma and its complications. Bull World Health Organ 1987;65(4):477-483. PubMed PMID: 3500800; PubMed Central PMCID: PMC2491032.

3. Grayston JT, Wang SP, Yeh $L$, Kuo CC. Importance of reinfection in the pathogenesis of trachoma. Rev Infect Dis 1985;7(6):717-725. PubMed PMID: 4070905.

4. Gambhir M, Basanez MG, Burton MJ, Solomon AW, Bailey RL, Holland MJ, et al. The development of an age-structured model for trachoma transmission dynamics, pathogenesis and control. PLoS Negl Trop Dis 2009;3(6):e462. doi: https://doi.org/10.1371/journal.pntd.0000462. PubMed PMID: 19529762; PubMed Central PMCID: PMCPMC2691478.

5. Burton $\mathrm{M}$, Solomon $\mathrm{A}$. What's new in trichiasis surgery? Community Eye Health 2004;17(52):52-53. PubMed PMID: 17491821; PubMed Central PMCID PMC1705745.

6. Habtamu E, Wondie T, Aweke S, Tadesse Z, Zerihun M, Zewudie Z, et al. Posterior lamellar versus bilamellar tarsal rotation surgery for trachomatous trichiasis in Ethiopia: a randomised controlled trial. Lancet Glob Health 2016; 4(3):e175-e184. doi: https://doi.org/10.1016/\$2214-109X(15)00299-5. PubMed PMID: 26774708; PubMed Central PMCID: PMCPMC5075282.

7. Rajak SN, Habtamu E, Weiss HA, Bedri A, Gebre T, Genet A, et al. Epilation for trachomatous trichiasis and the risk of corneal opacification. Ophthalmology. 2012;119(1):84-89. doi: https://doi.org/10.1016/j.ophtha. 2011.06.045. PubMed PMID: 21975041; PubMed Central PMCID: PMC3694301.

8. World Health Organization. WHO Alliance for the global elimination of blinding trachoma by the year 2020: progress report on elimination of trachoma, 2017. Wkly Epidemiol Rec. 2017;92(26):357-68.

9. Migchelsen SJ, Sepulveda N, Martin DL, Cooley G, Gwyn S, Pickering H, et al. Serology reflects a decline in the prevalence of trachoma in two regions of the Gambia. Sci Rep 2017;7(1):15040. doi: https://doi.org/10.1038/s41598017-15056-7. PubMed PMID: 29118442; PubMed Central PMCID: PMCPMC5678181.

10. Martin DL, Bid R, Sandi F, Goodhew EB, Massae PA, Lasway A, et al. Serology for trachoma surveillance after cessation of mass drug administration. PLoS Negl Trop Dis 2015;9(2):e0003555. doi: https://doi.org/10.1371/journal.pntd. 0003555. PubMed PMID: 25714363; PubMed Central PMCID: PMCPMC4340913.
11. Zambrano Al, Sharma S, Crowley K, Dize L, Munoz BE, Mishra SK, et al. The World Health Organization recommendations for trachoma surveillance, experience in Nepal and added benefit of testing for antibodies to chlamydia trachomatis pgp3 protein: NESTS study. PLoS Negl Trop Dis 2016; 10(9):e0005003. doi: https://doi.org/10.1371/journal.pntd.0005003. PubMed PMID: 27654497; PubMed Central PMCID: PMCPMC5031451.

12. Design and validation of a trachomatous trichiasis-only survey. Geneva: World Health Organization; 2017 (WHO/HTM/NTD/PCT/2017.08). License: CC BY-NC-SA 3.0 IGO.

13. Evans JR, Solomon AW. Antibiotics for trachoma. Cochrane Database Syst Rev 2011;(3):CD001860. doi: https://doi.org/10.1002/14651858.CD001860. pub3. PubMed PMID: 21412875.

14. Dolin PJ, Faal H, Johnson GJ, Minassian D, Sowa S, Day S, et al. Reduction of trachoma in a sub-Saharan village in absence of a disease control programme. Lancet. 1997;349(9064):1511-1512. PubMed PMID: 9167460.

15. Hoechsmann A, Metcalfe N, Kanjaloti S, Godia H, Mtambo O, Chipeta T, et al. Reduction of trachoma in the absence of antibiotic treatment: evidence from a population-based survey in Malawi. Ophthalmic Epidemiol 2001;8(23):145-153. PubMed PMID: 11471084.

16. World Health Organization. Validation of elimination of trachoma as a public health problem. WHO/HTM/NTD/2016, vol. 8. Geneva: World Health Organization; 2016.

17. Adamu MD, Mpyet C, Muhammad N, Umar MM, Muazu H, Olamiju F, et al. Prevalence of trachoma in Niger state, north Central Nigeria: results of 25 population-based prevalence surveys carried out with the global trachoma mapping project. Ophthalmic Epidemiol 2016;23(sup1):63-69. doi: https:// doi.org/10.1080/09286586.2016.1242757. PubMed PMID: 27918223.

18. Adamu Y, Macleod C, Adamu L, Fikru W, Kidu B, Abashawl A, et al. Prevalence of trachoma in Benishangul Gumuz region, Ethiopia: results of seven population-based surveys from the global trachoma mapping project. Ophthalmic Epidemiol 2016;23(sup1):70-76. doi: https://doi.org/10.1080/ 09286586.2016.1247877. PubMed PMID: 27918248.

19. Mpyet C, Muhammad N, Adamu MD, Muazu H, Umar MM, Abdull M, et al. Prevalence of trachoma in Bauchi state, Nigeria: results of 20 local government area-level surveys. Ophthalmic Epidemiol 2016;23(sup1):39-45. doi: https://doi.org/10.1080/09286586.2016.1238945. PubMed PMID: 27846369

20. Mpyet C, Muhammad N, Adamu MD, Muazu H, Umar MM, Alada J, et al. Trachoma mapping in Gombe state, Nigeria: results of 11 local government area surveys. Ophthalmic Epidemiol 2016;23(6):406-411. doi: https://doi.org/ 10.1080/09286586.2016.1230633. PubMed PMID: 27726459.

21. Mpyet C, Muhammad N, Adamu MD, Muazu H, Umar MM, Goyol M, et al. Prevalence of trachoma in Katsina state, Nigeria: results of 34 district-level surveys. Ophthalmic Epidemiol 2016;23(sup1):55-62. doi: https://doi.org/10. 1080/09286586.2016.1236975. PubMed PMID: 27775463.

22. Muhammad N, Mpyet C, Adamu MD, William A, Umar MM, Goyol M, et al. Mapping trachoma in Kaduna state, Nigeria: results of 23 local government area-level, population-based prevalence surveys. Ophthalmic Epidemiol 2016;23(sup1):46-54. doi: https://doi.org/10.1080/09286586.2016.1250918. PubMed PMID: 27918227.

23. Mpyet C, Muhammad N, Adamu MD, Muazu H, Umar MM, Goyol M, et al. Prevalence of trachoma in Kano state, Nigeria: results of 44 local government area-level surveys. Ophthalmic Epidemiol 2017;24(3):195-203. doi: https://doi. org/10.1080/09286586.2016.1265657. PubMed PMID: 28276755.

24. Solomon AW, Pavluck AL, Courtright P, Aboe A, Adamu L, Alemayehu W, et al. The global trachoma mapping project: methodology of a 34-country population-based study. Ophthalmic Epidemiol 2015;22(3):214-225. doi: https://doi.org/10.3109/09286586.2015.1037401. PubMed PMID: 26158580.

25. Schemann JF, Sacko D, Malvy D, Momo G, Traore L, Bore O, et al. Risk factors for trachoma in Mali. Int J Epidemiol 2002;31(1):194-201. PubMed PMID: 11914321.

26. Cumberland P, Hailu G, Todd J. Active trachoma in children aged three to nine years in rural communities in Ethiopia: prevalence, indicators and risk factors. Trans R Soc Trop Med Hyg 2005;99(2):120-127. doi: https://doi.org/ 10.1016/j.trstmh.2004.03.011. PubMed PMID: 15607339.

27. Taylor HR, West SK, Mmbaga BB, Katala SJ, Turner V, Lynch M, et al. Hygiene factors and increased risk of trachoma in Central Tanzania. Arch Ophthalmol 1989;107(12):1821-1825. PubMed PMID: 2597076.

28. Alene GD, Abebe $S$. Prevalence of risk factors for trachoma in a rural locality of North-Western Ethiopia. East Afr Med J 2000;77(6):308-312. PubMed PMID: 12858929 . 
29. Guraksin A, Gullulu G. Prevalence of trachoma in eastern Turkey. Int J Epidemiol 1997;26(2):436-442. PubMed PMID: 9169182

30. Roba AA, Wondimu A, Patel D, Zondervan M. Effects of intervention with the SAFE strategy on trachoma across Ethiopia. J Epidemiol Community Health 2011;65(7):626-631. doi: https://doi.org/10.1136/jech.2009.094763. PubMed PMID: 20693489.

31. West S, Lynch M, Turner V, Munoz B, Rapoza P, Mmbaga BB, et al. Water availability and trachoma. Bull World Health Organ 1989;67(1):71-75. PubMed PMID: 2706728; PubMed Central PMCID: PMC2491213.

32. Baggaley RF, Solomon AW, Kuper H, Polack S, Massae PA, Kelly J, et al. Distance to water source and altitude in relation to active trachoma in Rombo district, Tanzania. Tropical Med Int Health 2006;11(2):220-227. doi: https://doi.org/10.1111/j.1365-3156.2005.01553.x. PubMed PMID: 16451347.

33. Polack SR, Solomon AW, Alexander ND, Massae PA, Safari S, Shao JF, et al. The household distribution of trachoma in a Tanzanian village: an application of GIS to the study of trachoma. Trans R Soc Trop Med Hyg 2005;99(3):218-225. doi: https://doi.org/10.1016/j.trstmh.2004.06.010. PubMed PMID: 15653125.

34. West SK, Emerson PM, Mkocha H, McHiwa W, Munoz B, Bailey R, et al. Intensive insecticide spraying for fly control after mass antibiotic treatment for trachoma in a hyperendemic setting: a randomised trial. Lancet. 2006; 368(9535):596-600. doi: https://doi.org/10.1016/S0140-6736(06)69203-9. PubMed PMID: 16905024.

35. Emerson PM, Bailey RL, Mahdi OS, Walraven GE, Lindsay SW. Transmission ecology of the fly Musca sorbens, a putative vector of trachoma. Trans R Soc Trop Med Hyg 2000;94(1):28-32. PubMed PMID: 10748893.

36. Hafez MAM. Studies on the ecology of Musca sorbens Wied. In Egypt. Bulletin de la Société Entomologiqe d'Egypte. 1958;42(83):121.

37. Courtright P, Sheppard J, Lane S, Sadek A, Schachter J, Dawson CR. Latrine ownership as a protective factor in inflammatory trachoma in Egypt. $\mathrm{Br}$ J Ophthalmol 1991;75(6):322-325. PubMed PMID: 2043570; PubMed Central PMCID: PMCPMC1042373.

38. Progress on drinking water, sanitation and hygiene: 2017 update and SDG baseline. Geneva: World Health Organization (WHO) and the United Nations Children's Fund (UNICEF), 2017 Licence: CC BY-NC-SA 3.0 IGO.

39. Ramesh A, Kovats S, Haslam D, Schmidt E, Gilbert CE. The impact of climatic risk factors on the prevalence, distribution, and severity of acute and chronic trachoma. PLoS Negl Trop Dis 2013;7(11):e2513. doi: https://doi.org/10.1371/journal.pntd. 0002513. PubMed PMID: 24244768; PubMed Central PMCID: PMC3820701.

40. Habtamu E, Wondie T, Aweke S, Tadesse Z, Zerihun M, Zewdie Z, et al. Trachoma and relative poverty: a case-control study. PLoS Negl Trop Dis 2015;9(11):e0004228. doi: https://doi.org/10.1371/journal.pntd.0004228. PubMed PMID: 26600211; PubMed Central PMCID: PMCPMC4657919.

41. Zomer RJ, Trabucco A, Bossio DA, Verchot LV. Climate change mitigation: a spatial analysis of global land suitability for clean development mechanism afforestation and reforestation. Agric Ecosyst Environ. 2008;126(1):67-80. https://doi.org/10.1016/j.agee.2008.01.014.

42. Salim AR, Sheikh HA. Trachoma in the Sudan. An epidemiological study. Br J Ophthalmol 1975;59(10):600-604. PubMed PMID: 1191619; PubMed Central PMCID: PMC1017417.

43. ISRIC. World Soil Information, 2013. Soil property maps of Africa at $1 \mathrm{~km}$. www.isric.org.

44. Henderson JV, Storeygard A, Weil DN. A bright idea for measuring economic growth. Am Econ Rev 2011;101(3):194-199. doi: https://doi.org/ 10.1257/aer.101.3.194. PubMed PMID: PMC4112959.

45. Chen X, Nordhaus WD. Using luminosity data as a proxy for economic statistics. Proc Natl Acad Sci U S A 2011;108(21):8589-8594. doi: https://doi. org/10.1073/pnas.1017031108. PubMed PMID: PMC3102367.

46. Elvidge CD, Safran J, Tuttle B, Sutton P, Cinzano P, Pettit D, et al. Potential for global mapping of development via a nightsat mission. GeoJournal. 2007;69(1):45-53. https://doi.org/10.1007/s10708-007-9104-x.

47. Ebener S, Murray C, Tandon A, Elvidge CC. From wealth to health: modelling the distribution of income per capita at the sub-national level using night-time light imagery. Int J Health Geogr 2005;4:5-. doi: https://doi. org/10.1186/1476-072X-4-5. PubMed PMID: PMC549533.

48. Naimi B. R: Uncertainty analysis for SDMs: usdm-package.

49. Giorgi E, Diggle PJ. PrevMap: an R package for prevalence mapping. J Stat Softw. 2016.

50. Prost A, Negrel AD. Water, trachoma and conjunctivitis. Bull World Health Organ 1989:67(1):9-18. PubMed PMID: 2650903; PubMed Central PMCID: PMC2491216.
51. Hagi M, Schemann JF, Mauny F, Momo G, Sacko D, Traore L, et al. Active trachoma among children in Mali: clustering and environmental risk factors. PLoS Negl Trop Dis 2010;4(1):e583. doi: https://doi.org/10.1371/journal.pntd. 0000583. PubMed PMID: 20087414; PubMed Central PMCID: PMC2799671.

52. Clements AC, Kur LW, Gatpan G, Ngondi JM, Emerson PM, Lado M, et al. Targeting trachoma control through risk mapping: the example of southern Sudan. PLoS Negl Trop Dis 2010;4(8):e799. doi: https://doi.org/10.1371/ journal.pntd.0000799. PubMed PMID: 20808910; PubMed Central PMCID: PMC2923154.

53. Bobo LD, Novak N, Munoz B, Hsieh YH, Quinn TC, West S. Severe disease in children with trachoma is associated with persistent chlamydia trachomatis infection. J Infect Dis 1997;176(6):1524-1530. PubMed PMID: 9395364.

54. Burton MJ, Bowman RJ, Faal H, Aryee EA, Ikumapayi UN, Alexander ND, et al. The long-term natural history of trachomatous trichiasis in the Gambia. Invest Ophthalmol Vis Sci 2006;47(3):847-852. doi: https://doi.org/10.1167/ iovs.05-0714. PubMed PMID: 16505016.

55. Burton MJ, Bowman RJ, Faal H, Aryee EA, Ikumapayi UN, Alexander ND, et al. Long term outcome of trichiasis surgery in the Gambia. Br J Ophthalmol 2005;89(5):575-579. doi: https://doi.org/10.1136/bjo.2004.055996. PubMed PMID: 15834088; PubMed Central PMCID: PMC1772648.

56. Sahlu T, Larson C. The prevalence and environmental risk factors for moderate and severe trachoma in southern Ethiopia. J Trop Med Hyg 1992; 95(1):36-41. PubMed PMID: 1740817.

57. Garn JV, Boisson S, Willis R, Bakhtiari A, Al-Khatib T, Amer K, et al. Sanitation and water supply coverage thresholds associated with active trachoma: modeling cross-sectional data from 13 countries. PLoS Negl Trop Dis 2018; 12(1):e0006110. doi: https://doi.org/10.1371/journal.pntd.0006110. PubMed PMID: 29357365; PubMed Central PMCID: PMCPMC5800679.

58. Oswald WE, Stewart AE, Kramer MR, Endeshaw T, Zerihun M, Melak B, et al. Active trachoma and community use of sanitation, Ethiopia. Bull World Health Organ. 2017;95(4):250-60.

59. Katz J, Zeger SL, Tielsch JM. Village and household clustering of xerophthalmia and trachoma. Int J Epidemiol 1988;17(4):865-869. PubMed PMID: 3265700.

60. Broman AT, Shum K, Munoz B, Duncan DD, West SK. Spatial clustering of ocular chlamydial infection over time following treatment, among households in a village in Tanzania. Invest Ophthalmol Vis Sci 2006;47(1):99_ 104. doi: https://doi.org/10.1167/iovs.05-0326. PubMed PMID: 16384950.

61. Macharelli CA, Schellini SA, Opromolla PA, Dalben I. Spatial distribution of trachoma cases in the City of Bauru, state of Sao Paulo, Brazil, detected in 2006: defining key areas for improvement of health resources. Rev Soc Bras Med Trop 2013;46(2):190-195. doi: https://doi.org/10.1590/0037-8682-16322013. PubMed PMID: 23559341.

62. Schemann JF, Laffly D, Sacko D, Zephak G, Malvy D. Trichiasis and geoclimatic factors in Mali. Trans R Soc Trop Med Hyg 2007;101(10):9961003. doi: https://doi.org/10.1016/j.trstmh.2007.05.015. PubMed PMID: 17658570.

63. Smith JL, Sivasubramaniam S, Rabiu MM, Kyari F, Solomon AW, Gilbert C. Multilevel analysis of trachomatous Trichiasis and corneal opacity in Nigeria: the role of environmental and climatic risk factors on the distribution of disease. PLoS Negl Trop Dis 2015;9(7):e0003826. doi: https://doi.org/10.1371/ journal.pntd.0003826. PubMed PMID: 26222549; PubMed Central PMCID: PMCPMC4519340.

64. Engels D. The global trachoma mapping project: a catalyst for Progress against neglected tropical diseases. Ophthalmic Epidemiol 2016;23(sup1):12. doi: https://doi.org/10.1080/09286586.2016.1257139. PubMed PMID: 28030282; PubMed Central PMCID: PMCPMC5706979.

65. Rajak SN, Collin JR, Burton MJ. Trachomatous trichiasis and its management in endemic countries. Surv Ophthalmol 2012;57(2):105-135. doi: https://doi. org/10.1016/j.survophthal.2011.08.002. PubMed PMID: 22285842; PubMed Central PMCID: PMC3316859.

66. Rajak SN, Makalo P, Sillah A, Holland MJ, Mabey DC, Bailey RL, et al. Trichiasis surgery in the Gambia: a 4-year prospective study. Invest Ophthalmol Vis Sci 2010;51(10):4996-5001. doi: https://doi.org/10.1167/iovs. 10-5169. PubMed PMID: 20505197; PubMed Central PMCID: PMC3066607.

67. West SK, Munoz B, Mkocha H, Hsieh YH, Lynch MC. Progression of active trachoma to scarring in a cohort of Tanzanian children. Ophthalmic Epidemiol 2001;8(2-3):137-144. PubMed PMID: 11471083.

68. Burton MJ, Rajak SN, Hu VH, Ramadhani A, Habtamu E, Massae P, et al. Pathogenesis of progressive scarring trachoma in Ethiopia and Tanzania and its implications for disease control: two cohort studies. PLoS Negl Trop Dis 
2015;9(5):e0003763. doi: https://doi.org/10.1371/journal.pntd.0003763. PubMed PMID: 25970613; PubMed Central PMCID: PMCPMC4430253.

69. Conway DJ, Holland MJ, Bailey RL, Campbell AE, Mahdi OS, Jennings R, et al. Scarring trachoma is associated with polymorphism in the tumor necrosis factor alpha (TNF-alpha) gene promoter and with elevated TNF-alpha levels in tear fluid. Infect Immun 1997;65(3):1003-1006. PubMed PMID: 9038309; PubMed Central PMCID: PMC175081.

70. Beyene HB, Bekele A, Shifara A, Ebstie YA, Desalegn Z, Kebede Z, et al. Elimination of Guinea worm disease in Ethiopia; current status of the Disease's, eradication strategies and challenges to the end game. Ethiop Med J 2017;55(Suppl 1):15-31. PubMed PMID: 28878428; PubMed Central PMCID: PMCPMC5582630.

71. Fitzpatrick C, Sankara DP, Agua JF, Jonnalagedda L, Rumi F, Weiss A, et al. The cost-effectiveness of an eradication programme in the end game: evidence from Guinea worm disease. PLoS Negl Trop Dis 2017:11(10): e0005922. doi: https://doi.org/10.1371/journal.pntd.0005922. PubMed PMID: 28981510; PubMed Central PMCID: PMCPMC5628789.

72. Lehner B, Döll P. Development and validation of a global database of lakes, reservoirs and wetlands. J Hydrol 2004;296(1):1-22. doi: https://doi.org/10. 1016/j.jhydrol.2004.03.028.

Ready to submit your research? Choose BMC and benefit from:

- fast, convenient online submission

- thorough peer review by experienced researchers in your field

- rapid publication on acceptance

- support for research data, including large and complex data types

- gold Open Access which fosters wider collaboration and increased citations

- maximum visibility for your research: over $100 \mathrm{M}$ website views per year

At BMC, research is always in progress.

Learn more biomedcentral.com/submissions 